Journal of the Rubber Research Institute of Sri Lanka, (2009) 89, 9-19

\title{
Effect of different light regimes on above and below ground development of Hevea brasiliensis during early stage of growth
}

\author{
A M W K Senevirathna*, P K W Karunatillake*, P D Pathirana* \\ and V H L Rodrigo*
}

Received 2 October 2007; Accepted 2 November 2007

\begin{abstract}
Above and below ground development of rubber at early stage of growth was compared in response to full sunlight, 33, 55 and $77 \%$ natural shades. Rate of leaf expansion, leaf number, leaf area, inter-whorl shoot length and number of leaf whorls developed decreased with increasing shade. However the thermal duration expressed as degree days for the leaf expansion was lowest in the highest shade treatment. Total and component dry matter of rubber decreased with increasing shade. Dry matter partitioning to roots was greater compared to leaves and stems during first seven months with an increasing trend towards the highest shade while decreasing the above to below ground ratio of dry matter with increasing shade. After seven months, above ground development was prominent with an exponential increase in the plants grown under full sunlight.
\end{abstract}

Key words: above/below ground ratio, leaf development, natural shade, root length

\section{Introduction}

Rubber is grown commercially as mono-crop and mix-crop plantations on cleared lands exposed to full sunlight though it was originated and regenerated under the shade of overstorey canopies in natural forests. Whilst rubber is normally grown in plantation monocultures on large estates, on smallholdings it is more common to find rubber inter planted with a range of cash and food crops (Rodrigo et al., 2001a). In such mixed cropping systems, rubber often experiences shading during early stage of growth for about 1-2 years (Rodrigo et al., 2001b). Since many forest plant species explicit varied growth and development under different light conditions (e.g. Poorter, 2001; Valio, 2001), rubber should also respond differently to light in terms of above and below ground development.

Under the natural conditions of a cropping system, the quantity and quality of light incident on plants growing under shade may differ even under uniform clear sky conditions due to the effects of sunflecks and Red to Far-red ratio (R:FR) of sunlight. This ratio is lower in the understorey and the plants there experience more FR in photosynthesis (Lambers et al., 1998).

\footnotetext{
* Rubber Research Institute of Sri Lanka, Dartonfield, Agalawatta, Sri Lanka
} 
Light on above/below ground development of Hevea

Similarly, sunflecks contribute significantly for the photosynthesis of shade plants because, more than $50 \%$ of daily photosynthetic photon flux density (PPFD) received by them was from sunflecks (Pearcy, 1983, 1987). Therefore the light environments in natural and artificial shades are completely different and artificial shades do not account the effects of sunflecks and FR in growth and development of plants. In order to avoid such deficiencies, this study was carried out under natural shades provided by the canopies of mature rubber plantations to find the effects of different light regimes on above and below ground development of rubber at early stage of growth.

\section{Materials and Methods \\ Experimental site}

An existing rubber plantation at the Dartonfield Estate of the Rubber Research Institute of Sri Lanka was selected to provide different light levels to the experimental plants. The experiment consisted with four levels of growth irradiance: $0 \%, 33 \%, 55 \%$ and $77 \%$ reduction in full sunlight. Shade levels of 33, 55 and $77 \%$ were achieved with the combination of age and interrow spacing, and by selective pruning of branches of mature rubber trees in the selected plantation. An open area close to the three shade treatments was selected to provide full sunlight as the control. Shade levels were monitored by a Ceptometer (Delta-T Devices, UK) and by installing two solarimeters per treatment plot fixed above the canopies of the experimental plants and connected to the data logger (21X, Campbell Scientific Ltd., Leicestershire, UK) of the weather station (Campbell Scientific Ltd., Leicestershire, UK). In addition, daily maximum and minimum temperature were recorded using maximum and minimum thermometers (GMBH Co., Germay) in each experimental treatment.

\section{Experimental design}

Healthy plants of rubber (RRIC 100) that were $c a .8$ months old were used for planting (25 plants per each shade treatment). Trees were planted in single rows between the existing rows of mature rubber, keeping an intra-row spacing of $3.0 \mathrm{~m}$. To avoid competition with the roots of the mature rubber trees used to provide natural shade and to minimise variability in rooting conditions, all experimental plants were planted in soil-filled pits lined with a double layer of polythene film of gauge 500. Soil pits were excavated to a depth of $1.5 \mathrm{~m}$ and to a diameter of $1.8 \mathrm{~m}$ and the pits were refilled according to the original soil profile. Nested model was used whereby individual plants within a treatment were considered as single replicates.

\section{Crop husbandry}

Chemical fertilisers were
applied in accordance with
recommendations given by the Rubber
Research Institute of Sri Lanka. As the
plants were grown under the canopy of




\section{A M W K Senevirathna et al.}

mature rubber, the new rubber plants were sprayed during the rainy season at weekly intervals with Dithane M45 (3 g in 1 litre of water) and Captan (4 g in 1 litre of water) to prevent leaf diseases.

\section{Leaf development}

Five plants from each treatment that had a newly emerging fourth leaf whorl were selected and the length of time taken to reach full leaf expansion of the whorl was recorded. After reaching full leaf expansion, leaf area was measured using the portable leaf area meter and the inter-whorl length between the third and new leaf whorl was recorded. Degree days (thermal duration; ${ }^{\circ} \mathrm{Cd}$ ) to full expansion of the fourth leaf whorl were calculated using the following formula (Ong and Baker, 1985), and using the base temperature $\left(\mathrm{T}_{b}\right)$ for leaf emergence of rubber as 16 ${ }^{\circ} \mathrm{C}$ (Lemos Filho et al., 1993).

Thermal duration $=\mathrm{D}\left(\mathrm{T}-\mathrm{T}_{\mathrm{b}}\right)$ where, $\mathrm{D}$ is the duration of the development (days) and $\mathrm{T}$ is the mean air temperature $\left({ }^{\circ} \mathrm{C}\right)$. In addition, nondestructive measurements of number of leaves per whorl and total number of leaves and leaf whorls produced were recorded at bimonthly intervals.

\section{Root length density}

Soil samples from 0-0.3, 0.3-0.6 and $0.6-0.9 \mathrm{~m}$ depths from selected rubber plants, and from a $0.3 \mathrm{~m}$ distance from the main stem were taken using a soil core with a diameter of $0.08 \mathrm{~m}$ in order to analyse root length density. The length of the large roots of each sample was measured using a ruler, and the length of the fine roots was determined by measuring the area with the LI-3000 Leaf Area Meter and dividing by the average diameter of the root sample. The root length density (RLD) of each sample was calculated by dividing the total root length by the volume of the soil core sample.

\section{Above- and below-ground dry matter analysis}

Both above- and below-ground dry matter was assessed at 7, 14 and 17 months after planting (MAP) using five plants randomly selected from each treatment. Selected plants were totally uprooted and the total fresh weight of the components; leaves, stem and roots were measured separately, immediately after harvest. A sub-sample of $40 \%$ of the total fresh weight from each component was dried at $80{ }^{\circ} \mathrm{C}$ in a forced draught oven to a constant weight and total dry weights recorded (Rodrigo et al., 1997). The leaf area of each leaf whorl of rubber was measured using the LI-3000 Leaf Area Meter (Li-Cor Inc., USA). High shade treatment was not considered for the dry matter analysis at 17 MAP because of the fewer number of plants left due to damage by cattle.

\section{Data analysis}

Number of leaf whorls and leaves produced, plant dry weights, taproot length and RLD were analysed using the Nested procedure and SAS statistical package (SAS Institute Inc., 
Light on above/below ground development of Hevea

Cary, NC, USA). Whilst analysis of variance (ANOVA) and the General linear model (GLM) were used respectively for balanced and unbalanced data. The mean separation of treatments was performed with Duncan's multiple range test (DMRT) for the comparison of the treatment effects.

\section{Results}

Mean shade levels measured using a Ceptometer and logged with Solarimeters were $33( \pm 1.0) \%, 55$ $( \pm 0.5) \%$ and $77( \pm 0.7) \%$ respectively, in the low, medium and high shade treatments compared to the unshaded control for the period of study (Table 1, Fig. 1a). Daily mean air temperature was $28.2( \pm 0.1), 27.3( \pm 0.1), 27.2( \pm 0.1)$ and $26.0( \pm 0.1){ }^{\circ} \mathrm{C}$ in the unshaded control, low, medium and high shade treatments respectively (Fig $1 \mathrm{~b}$ ), whilst maximum temperature was $33.9( \pm 0.2)$, $32.1( \pm 0.1), 31.2( \pm 0.2)$ and $29.5( \pm 0.1)$ ${ }^{\circ} \mathrm{C}$ respectively in the four shade treatments (data not shown). The minimum temperature was on average ca. $22.5^{\circ} \mathrm{C}$ in all treatments.
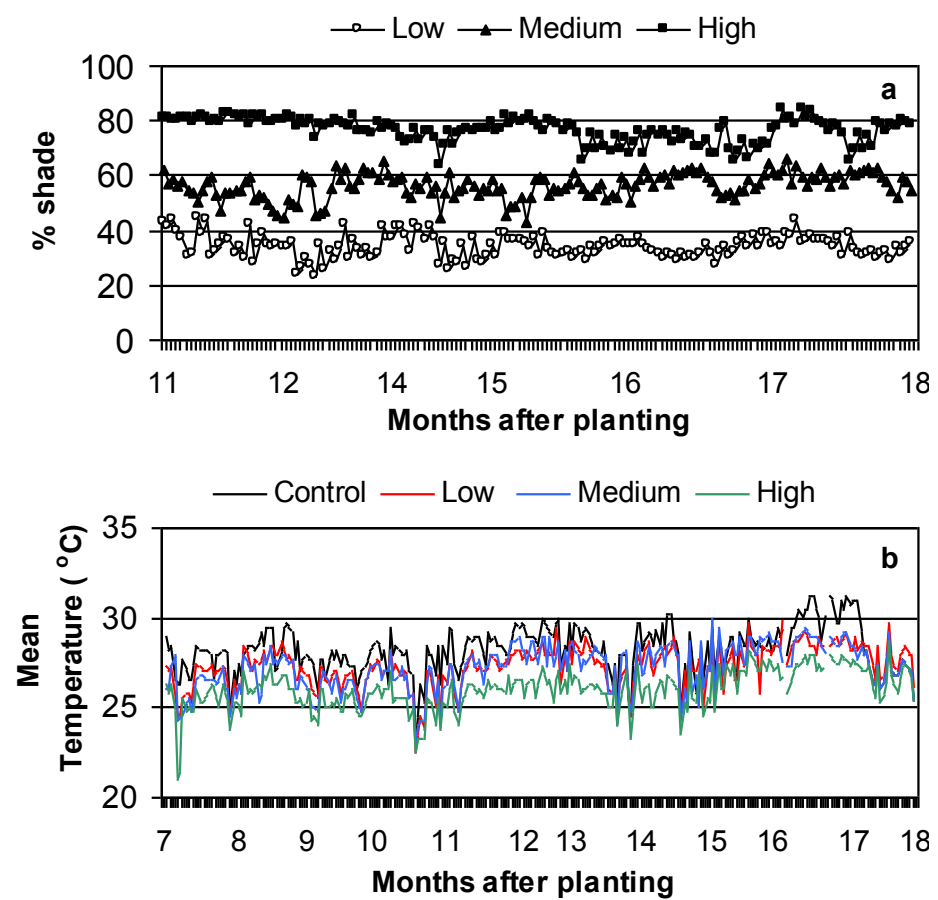

Fig. 1a. Mean shade levels in 'low', 'medium' and 'high' shade treatments logged with solarimeters hourly between 10:00 and 16:00 hours. b. Daily mean temperature the unshaded control, low, medium and high shade treatments in which the \% reduction in incoming radiation was $0,33,55$ and $77 \%$ respectively 
A M W K Senevirathna et al.

Table 1. Mean percentage reduction in incoming radiation (\% shade) for each shade treatment before and after selective pruning of the branches of the mature rubber trees providing the shade canopy. Periods labelled with an asterisk refer to measurements taken prior to pruning and each value is the mean of a minimum of 50 measurements \pm s.e.m. taken up to 10 months from planting

\begin{tabular}{cccc}
\hline Months after planting & Low shade & Medium shade & High shade \\
\hline Before planting & $29.8 \pm 0.8$ & $54.1 \pm 1.5$ & $75.4 \pm 1.3$ \\
$* 5$ & $33.1 \pm 1.2$ & $55.3 \pm 1.4$ & $77.2 \pm 1.3$ \\
6 & $30.0 \pm 0.9$ & $53.6 \pm 1.3$ & $75.8 \pm 1.4$ \\
$* 10$ & $35.4 \pm 0.8$ & $56.9 \pm 1.1$ & $79.5 \pm 1.2$ \\
10 & $34.9 \pm 1.1$ & $55.8 \pm 0.8$ & $78.6 \pm 0.8$ \\
\hline
\end{tabular}

The number of leaf whorls and leaves developed decreased with increasing shade (Fig. 2). The highest number of leaf whorls and leaves produced were $9( \pm 0.3)$ and $177( \pm 6)$, respectively in the unshaded control at 15 months after planting (MAP) $(p<0.001)$, whilst the lowest was in the high shade treatment where the total number of leaf whorls and leaves was 6 $( \pm 0.5)$ and $66 \quad( \pm 10)$, respectively. Expansion of the fourth leaf whorl is summarised in Figure 3. The maximum number of leaves produced was $26( \pm 1)$ in the unshaded control and the minimum was $17( \pm 1.5)$ in the high shade treatment (Fig. 3a). The maximum leaf area achieved at full expansion of the whorl was $57 \%$ greater in the unshaded control than under low shade, with values similar across low and medium shade and lowest in the high shade treatment (Fig. 3b). The length of the inter-whorl shoot between the third and fourth leaf whorls was also lowest in the high shade treatment, with the highest values in the unshaded control and low shade treatment (Fig. $3 c)$. The high shade required the lowest number of degree-days $\left(294 \pm 7{ }^{\circ} \mathrm{Cd}\right)$ to reach full leaf expansion (Fig. 3d). During the period of leaf expansion, percentage leaf fall due to infection by Colletotrichum gloeosporioides was 7.5, 15,15 and $16 \%$ respectively in the control, low, medium and high shade treatments (data not shown). 
Light on above/below ground development of Hevea
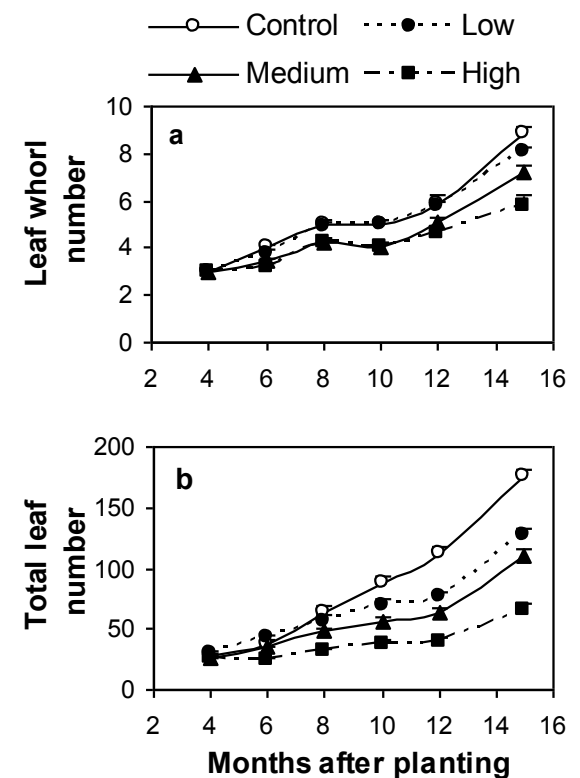

Fig. 2. Number of leaf whorls (a) and leaves (b) developed in plants grown under the unshaded control, low, medium and high shade treatments in which the \% reduction in incoming radiation was $0,33,55$ and $77 \%$, respectively
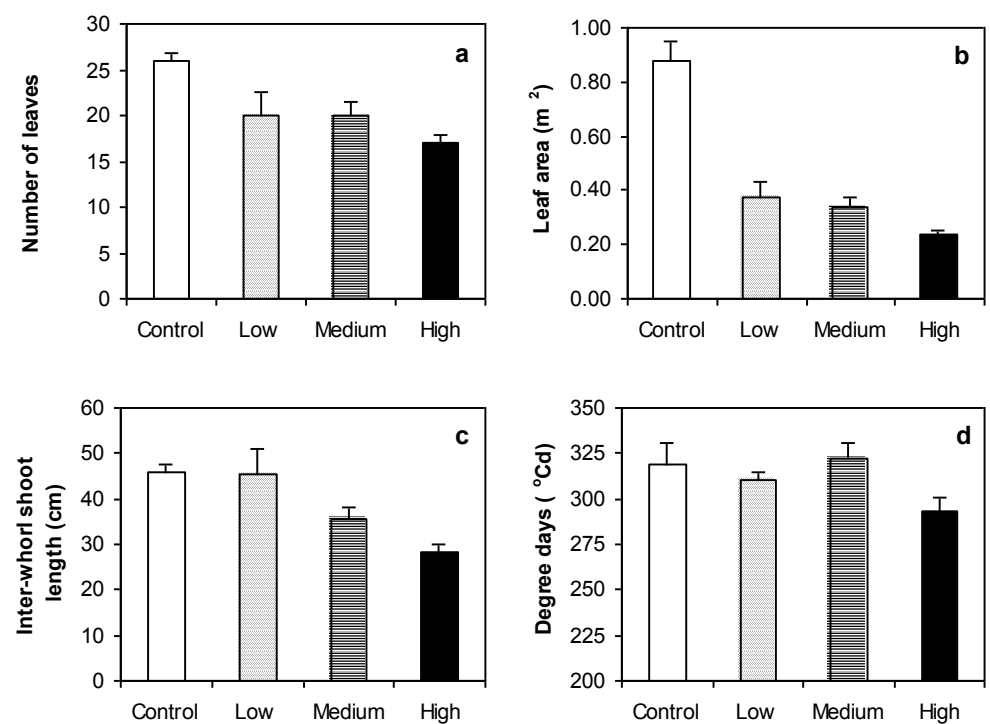

Fig. 3. Development of the fourth leaf whorl of rubber; $\mathbf{a}$. total leaf number; $\mathbf{b}$. maximum leaf area c. length of inter-whorl shoot; and $\mathbf{d}$. degree days to reach full leaf expansion in the unshaded control, low, medium and high shade treatments in which the $\%$ reduction in incoming radiation was $0,33,55$ and $77 \%$, respectively 


\section{A M W K Senevirathna et al.}

Total and component dry matter of rubber decreased with increasing shade at 7, 14 and 17 MAP (Fig. 4a). At 7 months, partitioning of dry matter to roots $(47.6 \pm 3.1 \%)$ was, on average, higher than that to stems $(36.1 \pm 1.5 \%)$ or leaves $(16.3 \pm 1.7 \%)$, whereas after 14 months, stems contributed most to total dry matter (Fig. 4a). By 17 MAP, the contribution of dry matter to stems was on average $55.7 \%( \pm 1.6)$ and higher than that to roots $(34.4 \pm 2.1 \%)$ or leaves $(10.2 \pm 0.7 \%)$. Partitioning to above ground structures of rubber significantly increased with age ( $p<0.05$; Fig. $4 \mathrm{~b})$. At 7 months, above to below ground ratio was significantly lower $(p<0.05)$ in the two highest shade treatments compared to the control. There was a declining trend of above to below ground ratio with increasing shade at 14 and 17 MAP too; values were similar in the low and high shade treatments, and those were significantly less $(p<0.05)$ than the control and medium treatments at 14 MAP (Fig. 4b).
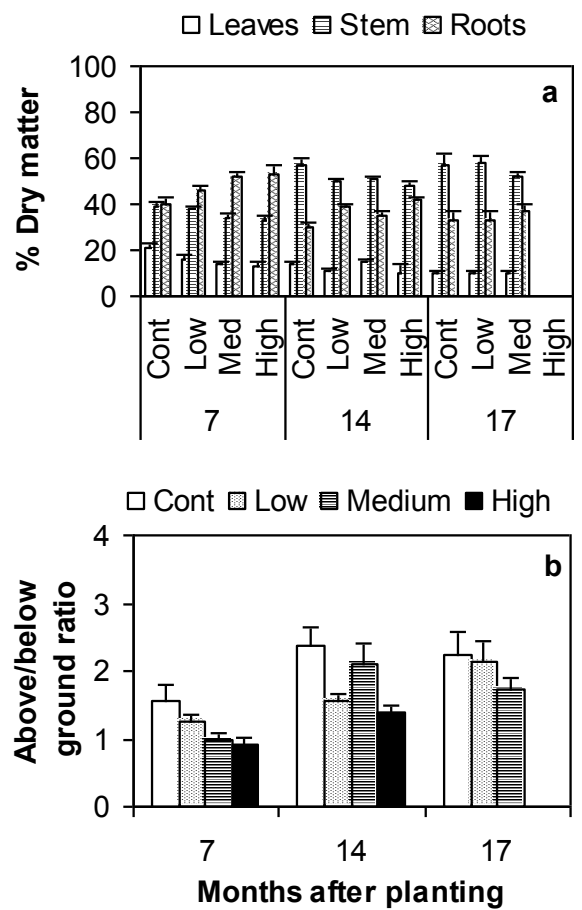

Fig. 4. Percentage component dry matter (a) and Above/Below ground dry matter ratio (b) of rubber grown under the unshaded control, low, medium and high shade treatments where the $\%$ reduction in incoming radiation was $0,33,55$ and $77 \%$, respectively. Data represent means \pm s.e.m of 5 replicate plants per treatment 
Taproot development was greatest in the least shaded treatments, reaching a maximum depth of $1.0 \mathrm{~m}$ in the control at 7 MAP, 1.1-1.2 m by 14 MAP and 1.3-1.4 m by 17 MAP in both the control and low shade treatments (Fig. 5a). Analysis of root length density (RLD) of rubber showed that lateral root development occurred within the top $0.9 \mathrm{~m}$ of soil in the low shade and control treatments even at
7 MAP (Fig. 5b). In the high shade treatment lateral roots were confined to the top $0.6 \mathrm{~m}$ depth even after 14 MAP; no comparison was possible in this treatment at $17 \mathrm{MAP}$, as the highest shaded rubber was excluded from the growth analysis at $17 \mathrm{MAP}$ due to cattle damage. There was no significant treatment effect on RLD at 17 MAP $(p>0.05)$.
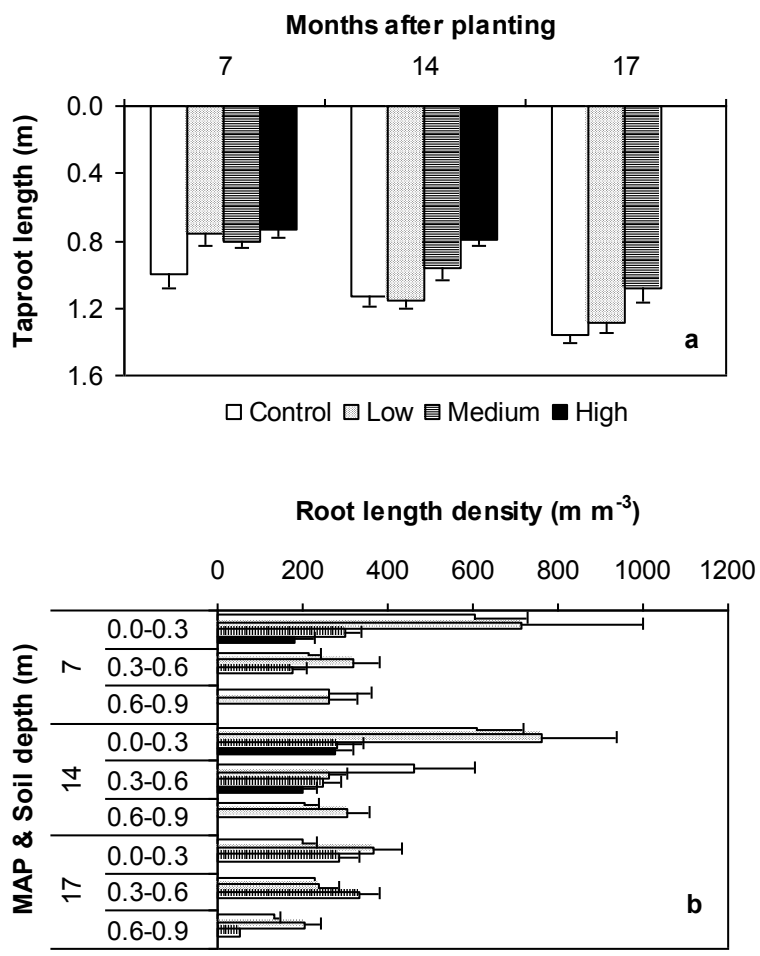

Fig. 5. Length of the taproot (a) and root length density at 0-0.3, 0.3-0.6 and 0.6-0.9 m depths (b) at 7, 14 and 17 months after planting (MAP) in the unshaded control, low, medium and high shade treatments where the $\%$ reduction in incoming radiation was $0,33,55$ and $77 \%$, respectively. Data represent means \pm s.e.m of 5 replicate plants per treatment 


\section{A M W K Senevirathna et al.}

\section{Discussion}

As expected mean air temperature by $1.4{ }^{\circ} \mathrm{C}$ (Fig. 1b) and photosynthetic photon flux density (PPFD) by $56 \%$ (Senevirathna et al., 2003) were low on average in shade treatments compared to the unshaded control. Although the mean temperature variation among treatments was small, the difference in average daily maximum temperature between the heavy shade and the control was $4.4{ }^{\circ} \mathrm{C}$. Since PPFD and air temperature were comparatively low in shade treatments and natural shades were imposed by existing rubber plantations, microclimatic conditions such as \% RH, air turbulence etc. are expected to be different to those in the control. Because of those changes in environmental conditions, above and below ground development of rubber differed in tested light regimes.

Slow growth rate with increasing shade is evident by declined rate of leaf expansion expressed as reduced leaf number, leaf area and interwhorl shoot length of rubber grown under shade (Fig. 3). As a result, number of leaf whorls and leaves produced under shade were low compared to those under full sunlight (Fig. 2). Although the number of days taken for fully development of a leaf whorl increased with increasing shade (Senevirathna et al., 2003), thermal duration (degree days) for the same revealed the lowest degree days in the highest shade treatment (Fig. 3d) reflecting that the temperature discrepancy among treatments has a significant role in the growth and development of rubber. Shade responses in relation to the growth and development of rubber observed in this study agree with those observed in some forest tree species (Poorter, 2001; Valio, 2001) except reduced leaf area and inter-whorl shoot length of heavily shaded rubber. Reduced leaf area in high shade could be a result of less number of leaves produced, smaller leaf size and relatively higher leaf fall due to foliar infections at leaf emergence.

Partitioning of dry matter indicated that at the phase of plant establishment, below ground partitioning was greater during the period of first 7 months as reflected by the higher percentage of root biomass (Fig. 4a) and low above/below ground ratio of dry matter (Fig. 4b) during this period. Furthermore, the dry matter partitioning to roots increased with increasing shade and concomitantly above/below ground ratio of biomass decreased with increasing shade for the same period. This revealed that plants grown under shade require more photosynthates for the early field establishment rather than for the above ground development. After 7 months, dry matter partitioning was greater to the above ground structures with higher values in the unshaded plants. Because of this, the photosynthetic productivity was high in the unshaded plants (Senevirathna et al., 2003) and lead to a superior growth rate over the shaded plants. Since the development rate is 
Light on above/below ground development of Hevea

high in the plants grown under full sunlight, taproot development up to a metre and lateral and fine roots up to a $0.9 \mathrm{~m}$ depth at 7 months was observed (Fig. 5) coinciding with the higher rate of above ground development. However, the taproot development of unshaded plants was slower after 7 months and grown only up to a length of $1.4 \mathrm{~m}$ after 17 months of planting indicating the higher rate of above ground development after the period of establishment.

According to the results of this study, below ground development of rubber was prominent during the phase of establishment, i.e. during the period of first 7 months with increasing proportions from full sunlight to heavy shade conditions. However, thereafter the above ground development was exponentially increased in plants grown under full sunlight compared to that in shade plants. Therefore, shade responses in above and below ground development of rubber should be taken into consideration when selecting tree crops for mixed cropping with rubber, especially the fast growing tree crop species.

\section{Acknowledgements}

We wish to thank the Rubber Research Institute of Sri Lanka for providing land for the experiment and supporting staff at the institute for valuable assistance in the field. Our thanks are extended to Dr. (Mrs.) Wasana Wijesuriya, Biometrician of the Rubber Research Institute of Sri Lanka for her great assistance in analysing data.

\section{References}

Lambers, H, Chapin III, F S and Pons, T L (eds.) (1998). Plant Physiological Ecology. Springer-Verlag, New York.

Lemos Filho, J P de, Villa Nova, N A and Pinto, H S (1993). Base temperature and heat units for leaf flushing emission and growth of Hevea brasiliensis Muell. Arg. Int. J. Biometeorol. 37, 65-67.

Ong, C K and Baker, C K (1985). Temperature and leaf growth. In: Baker, N R, Davies, W J and Ong, C K (eds.). Control of leaf growth. Cambridge University Press, UK. pp. 175-200.

Pearcy, R W (1983). The light environment and growth of $\mathrm{C}_{3}$ and $\mathrm{C}_{4}$ tree species in the understorey of a Hawaiian forest. Oecologia 58, 19-25.

Pearcy, R W (1987). Photosynthetic gas exchange responses of Australian tropical forest trees in canopy, gap and understorey microenvironments. Func. Ecol. 1, 169-178.

Poorter, L (2001). Light-dependant changes in biomass allocation and their importance for growth of rain forest tree species. Func. Ecol. 15, 113-123.

Rodrigo, $\mathrm{V} \quad \mathrm{H}$ L, Stirling, $\mathrm{C} \mathrm{M}$, Narampanawa, R M A K B and Herath, P H M U (2001a). Intercropping of immature rubber in Sri Lanka: present status and financial analysis of rubber intercrops planted at three densities of banana. Agroforestry Systems 51, 35-48.

Rodrigo, V H L, Stirling, C M, Teklehaimanot, $\mathrm{Z}$ and Nugawela, A (2001b). Intercropping with banana to improve fractional interception and radiation-use efficiency of immature rubber plantations. Field Crops Research 69, 237-249. 
A M W K Senevirathna et al.

Senevirathna, A M W K, Stirling, C M and Rodrigo, V H L (2003). Growth, photosynthetic performance and shade adaptation of rubber (Hevea brasiliensis Muell. Arg.) grown in natural shade. Tree Physiology 23, 705-712.

Valio, I F M (2001). Effects of shading and removal of plant parts on growth of Trema micrantha seedlings. Tree Physiology 21, 65-70.
Address for correspondence: Dr A M W K Senevirathna, Botanist, Rubber Research Institute of Sri Lanka, Dartonfield, Agalawatta, Sri Lanka.

E-mail:wasan@sltnet.lk,dirrri@sltnet.lk 